\title{
GENDER DIFFERENCES IN CARDIOVASCULAR RESPONSE TO UPPER EXTREMITIES ISOMETRIC EXERCISES IN NORMOTENSIVE SUBJECTS
}

\author{
Journal website at; \\ http://mrtbjournal.org/index.pllp/lijmr/issue/current/showToc
}

\author{
*CE MBADA, **OA AKINWANDE, ****JF BABALOLA, **OR SEYI-ADEYEMO, ODEJIDE AS* \\ * Physiotherapy Department, Obafemi Awolowo University Teaching Hospital Complex (OAUTHC), \\ Ile-Ife, Osun State, Nigeria. \\ ** Physiotherapy Department, University College Hospital, Ibadan, Nigeria. \\ *** Department of Human Kinetics and Health Education, University of Ibadan, Nigeria.
}

\author{
Correspondence to: \\ Chidozie E. Mbada. \\ Email: doziembada@yahoo.com.
}

Phone: +2348028252543

\section{SUMMARY}

Background and objective: Studies on gender differences in cardiovascular responses to isometric exercise have been numerous and conflicting. The objective of this study was to determine if the cardiovascular responses to upper extremities isometric exercises differ between apparently healthy male end female subjects.

Methods: One hundred and sixty apparently healthy adults with the mean age of $39.0 \pm 11.04$ years were consecutively recruited into the study. This consisted of 80 males ( 39.0 \pm 10.82 years) and 80 females $(38.96 \pm 11.25)$. Data were obtained on participants' age, height, weight, body mass index, blood pressure, heart rate, and Rate Pressure Product. Data were summarized using descriptive statistics of mean and standard deviation. Independent -test was used to compare physical characteristics between genders while repeated measure of ANOVA was used to compare the pre and post isometric exercises cardiovascular parameters between genders. Level of significance for all tests was set at $\mathrm{p}<0.05$.

Results: The baseline cardiovascular parameters were not significantly different $(p>0.05)$ between the male and the female participants. The post exercise cardiovascular parameters were significantly greater $(p<0.05)$ than the baseline values without gender bias. However, the post exercise SBP and RPP were significantly different $(\mathrm{p}<0.05)$ between the male and the female participants respectively. Conclusion: Isometric exercises of the upper limbs can lead to a significant increase in cardiovascular parameters among apparently healthy male and female subjects. Higher ventricular contraction is evoked among males leading increased SBP while the myocardial oxygen uptake and the measure of the oxygen consumption of the heart muscles of the female participants in response to upper extremities isometric exercises is higher than that of the males as demonstrated by the RPP.

Key words: Isometric exercises, cardiovascular response, upper extremities exercises.

\section{INTRODUCTION}

Isometric exercise has been reported to lead to increases in heart rate, systolic blood pressure, and diastolic blood pressure (Humphreys and Lind, 1963; Lind et al, 1964; Tipton, 1991; Arrol and Beaglehole, 1992; Cable T, 1998; Stendig-Lindberg, 2004). The larger the inuscle groups that are involved in isometric tension the greater the consequent cardiovascular responses to it (Mitchell et al, 1980; Seals et al, 1983). Inspite of this, isometric exercise remains an important modality in patients' rehabilitation among physical therapists. It has been reported to be effective in preventing a substantial loss of muscle mass and function during the period of recovery from an injury with joint immobilization (Astrand and Rodahl, 1977). Different forms of isometric exercises e.g. functional isometrics have been employed in some advanced training programmes (Jackson et al 1985) and also in strength and endurance trainning (Fox and Matthews 1981).

Cardiovascular response to exercise has been used as major criteria in exercise prescription for both the patients and healthy population (Banner et al, 1989; 
Laughlin 1999). Noteworthy attempts abound in explaining the mechanisms responsible for the cardiorespiratory changes to exercise in health and in disease states but they are at best inconclusive and conflicting (Astrand and Rodahl, 1977; Seals et al, 1983; Petrofsky and Phillips, 1986; Mohrman, 1997; Laughlin, 1999; Melrose, 1999). Also, the proposed mechanisms attempting to explain gender differences in cardiovascular responses to isometric exercise have been numerous and conflicting (Melrose, 1999). However, it has been noted that the substantial anatomical, physiological, and morphological differences that exist between men and women may affect their exercise capacity and influence the magnitude of response to exercise (Gatzke, 2005). The objective of this study was to determine if the cardiovascular responses to upper extremities isometric exercises differ between apparently healthy male end female subjects.

\section{MATERIALSAND METHODS}

One hundred and sixty ( 80 males and 80 females) apparently healthy adults whose ages ranged between 20 and 59 years and comprises of clinical students and staffs of the University College Hospital, Ibadan, Nigeria were recruited consecutively into this study. The eligible participants reported no previous history of cardiovascular or neurological condition on interview. On observation the participants were screened to eliminate any disability liniting the ability to exercise with the upper extremities. The informed consent of the participants was obtained before the commencement of the study. Data were obtained on participants' age, height, weight, blood pressure, heart rate and Rate Pressure Product (RPP).

\section{Instrumentation}

Metric Scale: Hanson Model, China was used to measure weight to the nearest $0.1 \mathrm{~kg}$ Height meter: A meter rule with calibration obtained by attachment of an inelastic tape measurement (Butterfly brand, China) was used to measure height to the nearest $0.1 \mathrm{~cm}$. Sphygmomanometer: An Accousson mercury-in-glass sphygmomanometer (Yamasu model, Japan) was used to measure blood pressure in millimetre mercury (mmHg). Stethoscope: A Littman stethoscope (U.S.A) was used was used with the Sphygmomanometer to measure the blood pressure.

Stop watch: Heuer, Track mate brand stop watch was used to time the duration of exercise and heart rate.

Hand held dynamometer: Takei Kiki Kogyo dynamometer was used for modified isometric strength exertion of the upper extremities with the participants in the upsianding position (Eess, 1995: Hamilton et al, 1954; Stephens et al, 1906

\section{Froceringe}

The participanis were fully informed about the purpose of the study and their consents were obtained. They were interviewed to ensure they met the study's inclusion criteria. The participants' biodata were taken and recorded. The baseline cardiovascular parameters were taken and recorded. The participants in the upstanding position performed 3 upper extremities isometric exercise for 3 minutes which comprises of two repetitions of pushing against the wall with the outstretched arms for 30 seconds each and they were instructed to exert maximal tension on the wall. Two repetitions of isometric contractions using the hand grip dynamometer, the participants were in the upstanding position with the arms fully extended by the side of the body and they were instructed to exert maximal tension on the hand grip dynamometer and hold it for 30 seconds. Two repetitions of isometric contractions with the hands clasped together and brought to the manubrosternal level of the chest while the shoulders are $60^{\prime \prime}-70^{\circ}$ abducted (winged). The participants were instructed to maximally generate tension by pressing the opposite hands against each other in the exercise position and hold it for 30 seconds. During the exercises the participants were instructed to avoid Valsalva maneuver by not holding their breath and were instructed to do rhythmic breathing in order to minimize the pressor response. On completion of the three isometric exercise bouts, the post exercise cardiovascular parameters were measured. Thereafter, the participants were asked to rest for 10 minutes before discharge.

\section{Computations}

The Rate Pressure Products (RPP), which is a useful index of the cardiac stress and is known to be a valid predictor of the myocardial oxygen consumption at rest and during exercise, was evaluated using the formula;

RPP = SBP $\times$ HR (Pollock and Wilmore, 1990; Balogun et al, 1990).

\section{Statistical analyses}

Data was analyzed using the Statistical Package for Social Sciences [SPSS] version 11.0. (SPSS Inc., Chicago, Illinois, USA). Descriptive statistics of mean and standard deviation were used to summarize the data and independent t-test was used to compare the participants' physical characteristics by gender: Repeated measures ANOVA and Duncan post hoc test was used to compare the resting and post isometric exercises cardiovasculair parameters by gender. Level of significance for all tests was set at $p<0.05$.

\section{RESULTS}

A worai of 160 apparently healthy adults participated in this siludy with the mean age of $39.0 \pm 11.04$ years. The pinysical characteristics of the participants by gender are presented in Table 1. The males and females were age matched with no significant differences in their height and weight respectively. However, the BNII of the female participants was significant $(t=-4.360 ; p>0.001)$ greater than that of the males. This indicates that the females had 
higher level of adiposity than their male counterparts. Repeated measures ANOVA and Duncan post hoc test comparison of the resting and post isometric exercises cardiovascular parameters by gender is presented in Table 2. There were significant differences between the resting and post isometric cardiovascular parameters (HR, SBP, DBP and RPP) without gender bias. The baseline cardiovascular parameters were not significantly different between the male and the female participants. However, the post exercise SBP and RPP were significantly different between the male and the female participants respectively. The male participants had a higher post exercise SBP level than the females while the females had a higher post exercise RPP level than the males. These results indicate that more blood is pumped by the left ventricle into the aorta in response to upper extremities isometric exercise among males than females; while the myocardial oxygen uptake and the measure of the oxygen consumption of the heart muscles of the female participants in response to upper extremities isometric exercises is higher than that of the males. The level of significance was set at $p<0.05$.

Table 1: Physical characteristics of the participants by gender.

\begin{tabular}{lccccc}
\hline Variable & $\begin{array}{l}\text { Male }(\mathbf{n}=8 \mathbf{8 0}) \\
\text { Mean } \pm \text { S.D }\end{array}$ & $\begin{array}{l}\text { Female }(\mathbf{n = 8 0}) \\
\text { Mean } \pm \text { S.D }\end{array}$ & $\mathrm{t}$ & $\overline{\text { p-value }}$ \\
\cline { 2 - 6 } Age $(\mathrm{yrs})$ & $39.0 \pm 10.82$ & $38.96 \pm 11.25$ & 0.043 & 0.966 \\
Height $(\mathrm{m})$ & $1.66 \pm 0.07$ & $1.64 \pm 0.06$ & 1.655 & 0.100 \\
Weight $(\mathrm{Kg})$ & $65.3 \pm 5.03$ & $66.6 \pm 7.95$ & 1.769 & 0.079 \\
BMI $\left(\mathrm{Kg} / \mathrm{m}^{2}\right)$ & $21.9 \pm 6.44$ & $24.7 \pm 5.32$ & -4.360 & $0.001^{*}$ \\
\hline
\end{tabular}

* indicate significant difference ( $p$ is significant at 0.05 )

$\mathrm{BMI}=$ Body mass index. $\mathrm{S} . \mathrm{D}=$ Standard deviation

\section{DISCUSSION}

This study investigated the gender differences in cardiovascular response to upper extremities isometric exercises among apparently healthy subjects. There was no significant difference in the physical characteristics of the participants by gender. However, the measure of adiposity as indicated by BMI was significantly higher among women than men. The result of this study showed that the post exercises heart rate, systolic blood pressure: diastolic blood pressure and rate pressure product respectively were significantly higher than the pre-exercise values. Therefore, upper extremities isometric exercises had a significant effect on the heart rate, systolic blood pressure, diastolic blood pressure and rate pressure product respectively. These findings supports the results of previous investigators that have shown that upon initiating isometric tension, increases in heart rate, systolic blood pressure, and diastolic blood pressure occur (Mitchell and Wildenthal, 1974; Mitchell et al, 1981; Seals et al, 1988; Verhaaren et al, 1994; Howden et al, 2006).

The finding of this study revealed no significant gender differences in the cardiovascular parameters of the participants at baseline. However, only SBP demonstrated a significant gender bias in response to upper extremities isometric exercises. Several investigations have measured cardiovascular response to isometric exercise between genders (Sanchez et al, 1980; Ettinger et al, 1996; Jones et al, 1996). The results of these investigations have been reported at best inconsistent (Jones et al, 1996; Melrose, 1999) and do not seem to follow a definite pattern. Sanchez et al (1980) found that sustained isometric contractions showed similar blood pressure responses between genders while Ettinger et al (1996) did show attenuated increases in blood pressure in females.

Table 2: Repeated measures ANOVA and Duncan post hoc test comparison of the resting and post isometric exercises cardiovascular parameters by gender.

\begin{tabular}{|c|c|c|c|c|c|c|}
\hline \multirow[b]{2}{*}{ Variables } & \multicolumn{2}{|l|}{ Male } & \multicolumn{2}{|c|}{ Female } & \multirow[b]{2}{*}{ F-ratio } & \multirow[b]{2}{*}{$P$ value } \\
\hline & $\begin{array}{l}\text { Pre-Ex } \\
\mathbf{X} \pm \text { S.D }\end{array}$ & $\begin{array}{l}\text { Post-Ex } \\
X \pm \text { S.D }\end{array}$ & $\begin{array}{l}\text { Pre-Ex } \\
X \pm \text { S.D } \\
\end{array}$ & $\begin{array}{l}\text { Post -Ex } \\
X \pm \text { S.D }\end{array}$ & & \\
\hline $\mathrm{HR}$ & $75.2 \pm 5.13^{\mathrm{a}}$ & $79.0 \pm 7.74^{b}$ & $74.9 \pm 7.08^{\mathrm{a}}$ & $79.8 \pm 7.43^{b}$ & 1.517 & $0.036^{*}$ \\
\hline SBP & $125.8 \pm 12.8^{2}$ & $130.6 \pm 12.5^{\circ}$ & $126.7 \pm 11.9^{2}$ & $128.7 \pm 13.8^{c}$ & 0.048 & $0.053^{*}$ \\
\hline DBP & $75.9 \pm 7.74^{a}$ & $79.0 \pm 7.58^{b}$ & $74.8 \pm 7.58^{\mathrm{a}}$ & $78.3 \pm 7.74^{b}$ & 1.290 & $0.036^{*}$ \\
\hline RPP & $9469.9 \pm 1108.1^{\mathrm{a}}$ & $9699.9 \pm 2730.0^{6}$ & $9416.9 \pm 1068.03^{\mathrm{a}}$ & $9786.81 \pm 2940^{a}$ & 33.67 & $0.042 *$ \\
\hline
\end{tabular}

* indicate significant difference.

Superscripts $(a, b, c)$.

For a particular variable, mode means with different superscript are significantly $(\mathrm{P}<0.05)$ different. Mode means with same superscripts are not significantly $(\mathrm{P}>0.05)$ different. The pair of cell means that is significant has different superscripts.

Key:

$\mathrm{S} . \mathrm{D}=$ Standard deviation

SBP = Systolic blood pressure

DBP $=$ Diastolic blood pressurt

$R P P=$ Rate pressure product 
The proposed mechanisms attempting to explain gender differences in cardiovascular responses to exercise have been numerous and conflicting (Melrose, 1999). Some studies that found significant gender differences in cardiovascular responses to static exercise believed it was due to differences in sympathetic-parasympathetic or adrenal interactions at the cardiac level (Sanchez et al, 1980; Ettinger et al, 1996). This present study found a significant gender difference in SBP in response to upper extremities isometric exercise with the males having higher mean SBP value. This corroborates an analysis of twelve gender comparison investigations that focused on isometric hand grip exercises and reported that men have greater SBP and catecholamine response to acute stress (Stoney et al, 1987).

The cardiovascular response to exercise has been used as major criteria in exercise prescription for both the patients and healthy population (Laughlin, 1999; Banner et al, 1989; ACSM, 1993; Wenger and Hellerstein, 1984). Defoyd (2000) advised that before beginning an exercise program, patients should be screened for cardiovascular risk factors, as well as signs and symptoms suggestive of cardiopulmonary disease. As the increase in arterial blood pressure secondary to static effort could cause a pressure overload of the heart, which can be dangerous for the persons with cardiovascular diseases (Mitchell et al, 1981; Grucza, 2007).

\section{CONCLUSION}

We conclude that isometric exercises of the upper limbs can lead to a significant increase in cardiovascular parameters of apparently healthy adults without gender bias. The result of this study demonstrated that more blood is pumped by the left ventricle into the aorta in response to upper extremities isometric exercise among males than females as indicated in the higher SBP among males than females. While the myocardial oxygen uptake and the measure of the oxygen consumption of the heart muscles of the female participants in response to upper extremities isometric exercises is higher than that of the males as demonstrated by the RPP. We recommend that assessment of cardiovascular risk factor prior to prescribing isometric exercise be carried out as a routine among physical therapists for healthy and patient populations without gender bias.

\section{REFERFNCES}

- American College of Sports Medicine (ACSM) (1993). Resource manual for guidelines for exercise testing and prescription, ed 2. Lea and Fabiger, Philadelphia.

- Arrol B and Beaglehole R (1992). Does physical activity lower blood pressure: A critical review of clinical trials, Journal of Clinical Epidemiology, 45, 439- 447.

(2) Astrand PO and Rodahl K (1977). Textbook of work physiology, McGraw-Hill, New York. pg 617.
- Balogun JA, Obajuluwa VA, Olaogun MO, Abereoje OK, Oyeyemi AY, Adeodu OO, Balogun MO (1990). Anthropometric determinants of resting blood pressures and heart rates of Nigerian school children. Annals of Tropical Paediatric. 10: $425-431$.

- Banner NR, Lloyd MH, Hamilton RD, Innes JA, Guz A, Yacoub MH. (1989). Cardiopulmonary response to dynamic exercise after heart and combined heart-lung transplantation. Br Heart J. 61(3): $215-23$.

- Cable T (1998). Blood Pressure and Exercise: American Fitness Professionals and Associates.

- Defoyd WD (2000). Cardiovascular fitness testing. In: Clinical application of outcome assessment. Yeoman SG, pp $373-390$.

- Appleton and Lange Ettinger S, Silber D, Collins B, Gray K, Sutliff G, Whisler S, McClain J, Smith M, Yang Q, Sinoway L. (1996). Influences of gender on sympathetic nerve responses to static exercise. J Appl Physiol; 80:245 251.

- Fess EE. (1995). Documentation: essential elements of upper extremity assessment battery, In: Hunter JM, Macklin EJ, Callahan AD eds. Rehabilitation of the Hand: Surgery and therapy: Vol 1. 4th ed. $185-214$. St Louis, MO: Mosby $\mathrm{CO}$.

- Fox E and Matthews D (1981). The physiological basis of Physical Education and Ath]etics, ed 3. Saunders College Publishing, Philadelphia.

- Gatzke A (2005): Gender Differences in Athletic Performance. How Women Differ from Men. ABC Body Building Company.

- Grucza R (2007): Cardiovascular response to static exercise. Institute of Sport, Trylogii 2/16, 01 - 892 Warsaw. Poland.

- Hamilton A, Balnave R, Adams R (1994). Grip strength testing reliability. J.Hand Therapy. 7: $163-170$.

- Howden RJ, Lightfoot T, Brown SJ, Swaine IL. (2002). The effects of isometric exercise training on resting blood pressure and orthostatic tolerance in humans. Cambridge Journal Online. 87: 507-515.

- Humphreys P and Lind A (1963). The blood flow through active and inactive muscles of the forearm during sustained handgrip contractions. J Physiol London; 166:120-135.

- Jackson AT, Jackson J, Hnatek, West J (1985). Strength development: using functional isometrics in an isotonic strength training program. Res. Q. Exerc. Sport. 56:234 237.

- Jones P, Spraul M, Matt K. Seals D, Skinner J, Ravussin E, (1996). Gender does not influence sympathelic neural reactivity to stress in healthy humans. Am J Physiol; 270 H350-H357.

- Laughlin MH (1999). Cardiovascular response to exercise Advances in physiology education: vol. 277, issue 6. 277 : $244 s-259$ s.

- Lind A, Taylor S, Humphreys P, Kcnelly B. Donald K. (1964). The circulatory effects of sustained voluntary muscle contractions. Clin Sci; 27; 229-244. 
- Melrose DR (2005). Gender differences in cardiovascular response to isometric exercise in the seated and supine positions. JEPonline,; 8(4):29 - 35.

- Mitchell J, Payne F, Saltin B, Schibye B, (1980). The role of muscle mass in the cardiovascular response to static contractions. J Physiol London; 309; 45 - 54.

- Mitchell JH and Wildenthal K (1974). Static (Isometric) Exercise and the Heart: Physiological and Clinical Considerations. Annual Review of Medicine: Vol. 25: $369-$ 381 .

- Mitchell JH, Schibye BF, Payne III C, Saltin B (1981). Response of arterial blood pressure to static exercise in relation to muscle mass, force development, and electromyographic activity. Circ. Res., Supp. I, 48: 170 175.

- Mohrman D, Heller L, Cardiovascular. Physiology 4th edition. New York: McGraw-Hill, 1997.

- Petrofsky J and Phillips C (1986). The physiology of static exercise. Med Sci Sports Exerc; 14: 1 - 44.

- Pollock MK, Wilmore JH (1990). Exercise in Health and Disease: Evaluation and Prescription for Prevention and Rehabilitation. USA. W.B Sanders, 55.

- Sanchez J, Pequignot J, Peyrin L, Monod H (1980). Sex differences in the sympatho-adrenal response to isometric exercise. Eur J Appl Physiol; 45:147 - 154.
- Seals DR, Washburn R, Hanson P, Painter P, Nagle F, (1983) Increased cardiovascular response to static contraction of larger muscle groups. J Appl Plysiol; 54(2): $434-437$.

- Seals DR, Chase PB, Taylor JA, (1988). Autonomic mediation of the pressor responses to isometric exercise in humans. J. Appl. Physiol. 64: 2190-2196.

- Stendig-Lindbelg G, (2004). Therapeutic exercises to improve and maintain physical fitness. Therapeutic exercise. eMedicine.

- Stephens JL, Pratt N, Parks B, (1996): The reliability and validity of the Tekdyne hand dynamometer: Part $1 . J$ Hand therapy. 9: $10-17$.

- Stoney C, Davis M. Matthews K (1987). Sex differences in physiological responses to stress and in coronary heart disease: a causal link? Psychophysiology; 24:127-131.

- Tipton CM (1991). Exercise, training and hypertension: An update. Exercise and Sports Science Reviews, 19; 447 506.

- Verhaaren HA, Schieken RM, Schwartz P, Mosteller M. Matthys D, Maes H, Beunen G Vlietinck R, and Derom R (1994). Cardiovascular reactivity in isometric exercise and mental arithmetic in children. J Appl Physio! 76: $146-150$

- Wenger HA, Reed AT (1976). Metabolic factors associated with muscular fatigue during aerobic and anaerobic work. Can J Appl Physiol 1:43-48. 